\title{
Automatic Grain Size Detection and Classification of Metals
}

\author{
${ }^{1-3}$ Electronics and Telecommunication Engineering Department, AISSMS, Institute of Information Technology, \\ Pune, India \\ Email:vbairagi@yahoo.co.in,mayurirathod16@gmail.com,rtushar.shirsath@gmail.com
}

Received: $24^{\text {th }}$ November 2018, Accepted: $13^{\text {th }}$ February 2019, Published: $3^{\text {th }}$ June $^{2019}$

\begin{abstract}
Metallography is the study of the microstructure of metallic alloys. The integrity of metals in vital in the case of any manufacturing industry as the durability is dependent on quality of metal. Microscopic analysis is essential part of modern manufacturing process. Micro-structural Inclusions measurement is routinely required process for maintaining quality. The most important physical properties of particulate samples are particle size and grain size. The diameter of individual grains of sediments is called as grain size. Gran size determination is actually depends upon the manual process which leading to time-consuming and errors are occur at the time of determination. The main objective to propose this system is to automatically analyze the material according to their size/shape and grain sizes. Fuzzy logic model is a classifier used to detect edges and corners of grains available in the input image. The system categories the metal using its grain size. The obtained results are compared with ASTM standards and other reported results in survey. The proposed system is useful in metal industry which are depends upon size and shape of the grains.
\end{abstract}

Keywords

Digital Input, Fuzzy Logic, Edge Detection, Grain Size Analysis.

\section{Introduction}

Metallography is important part of study related to the microstructure of metallic alloys. It can be stated that the scientific discipline of observing and analyzing the spatial distribution of the sediments, inclusions or phases present in metallic alloys. By extension, these similar principles can be applied to the further characterization of any material or alloy. Different techniques are used to reveal the micro structural characteristics of alloys [1]. An ultramicroscopic is a microscope with illumination system that allows viewing of tiny particles even up to size of micro meter level. Microscopic analysis is essential part of modern manufacturing process in metal industry. The quality, durability, and life cycle of a final product depend on the attribute and characteristics of the material with fitting tolerances. A defect in single sediment can lead to breakdown the entire end product of system. Micro-structural Inclusions measurement is routinely required process for maintaining quality. The most important physical properties of particulate samples are particle size and grain size.

The main objective to propose this system is to automatically analyze the material according to their size/shape and grain sizes. Grain size is diameter of individual grains of sediments. Grains are having internal boundaries to define grain size of metal. Grain size analysis acts an important part in the research of metallic material. From grains analysis we can get the information related to material's properties like yield strength, tensile strength and elongation which have effective impact on material's properties [22]. Grain size is "Diameter of individual particles". The methods of grain analysis are relying on the manual processes but it is time consuming and errors are liable to occur. So with the development of image processing technologies the DIP (Digital Image processing) and pattern recognition technologies can be used as tools for calculating the grain size automatically. Image-pro plus, image tool are widely used in metallographic process. This technique reduces manual workloads and improves the efficiency of analysis but it is difficult to identity grain boundaries in the image frame with low contrast and bad boundaries detected [22-27]. So we overcome these problems with this system using fuzzy logic.

\section{Existing System}

The analysis of grain size and their shape and to classify those according to their characteristics is great era now a days. Although the few systems are automatic so as to reduce manual workloads and, but instructions of the systems are still observed very difficult, e.g., many parameters need to be set manually and for further process it require user's interface. There is major need to improve the efficiency of analysis to large extent. There are number of technique for measurement of particle shape and size such as Laser diffraction particle sizing, Dynamic light scattering, and Automatic image analysis with microscope. Among this automatic image analysis with microscope is most effective and reduced cost technique. Recent papers in the field of study are studied and brief summary is presented here with.

Grayali. $\mathrm{N}$ et al. [2, 12], researcher utilizes Ultrasonic Velocity to detect average grain size. It is observed that, the ultrasonic velocity in low carbon steel has effects of carbon content and temperature. So by using increase in the temperature average grain size is determined. The required instrumentation for processing which is expensive. 
Palanichamy, P et al. [3], researcher used ultrasonic velocity method to analyze grain size of stainless steel metal. It is observed that the system is time consuming and feasible only for particular location of material.

Beecham. D et al.[4], Goebbels, K et al. [5], and Hecht, A et al.[6], had Utilized ultrasonic backscatter. It is observed that in this method, it is difficult to get information of the variation of grain size.

Raul David Serban et al. [7], laser diffraction method was performed on 54 sediments to determine the grain size analysis. It is observed that in the result of texture classification is highly consistent but as relative deviation increased and correlation decreases as pre-treatment advanced, so they affects on variability of sand fraction and $\mathrm{H} 2 \mathrm{O} 2$ rather affected on slit fraction.

S N Chirikov et al. [8], to calculate particle size and shape laser polarimetry and dynamic light scattering is used. It is observed that laser technique allows to analyze particle size of dispersed media remotely, efficiently and high sensitivity. Size determination is assumed based on medium particle are spherical. Accounting for the specific feature of particle shape is a difficult task requiring significant computing resources and partially difficult to resize.

Xincheng et al.[9], researcher utilized wavelet based edge detection technique for removing useless noise presented in the image, and it is observed that to characterize fractographs are very tedious and time consuming so to automate the process texture descriptor is utilizes.

Ben Luan et al. [10], researcher used New approach utilizes to reduce decomposition of Ni-p deposition solution and the drawback of the system is the trace amount of chlorine is under coating so it does not cause much of concern but the concentration of rinsing water is very low and Ni-P coated 3003 alloy have much higher hardness and wear resistance.

Łukasz Rauch et al. [11], researcher Utilizes feedback pulse coupled neural network is more efficient inspired by algorithms to segment the material microstructure images but it is observed that they analyze accurate edges and position of metals but they are not continuous and smooth.

\section{Methodology}

The block diagram of proposed system is shown below,

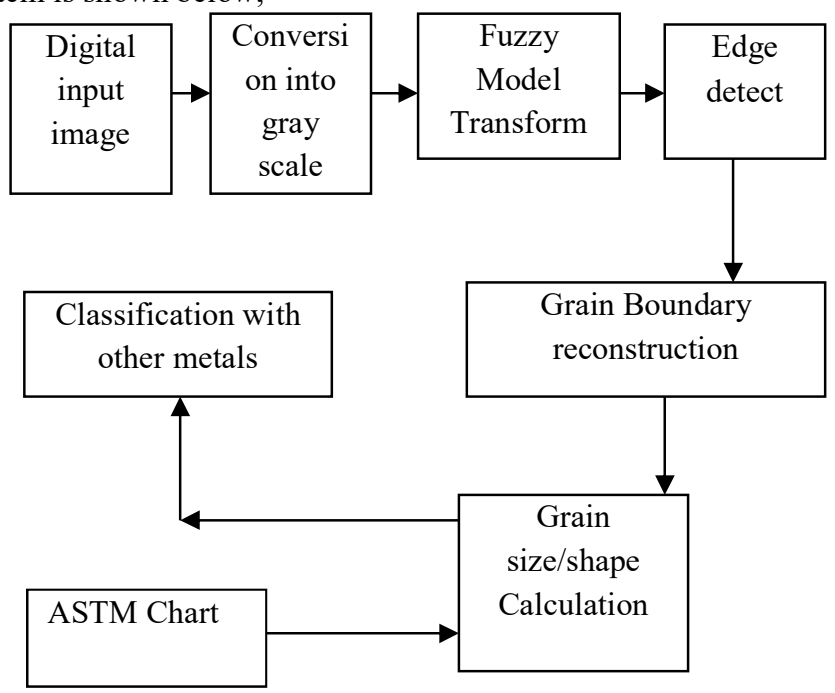

Overall System Description:

Figure 1: System Block Diagram

The digital image is given to the system as input as shown in fig.2. The digital image is converted into gray scale image shown in fig.3, because further we have to use fuzzy logic and for these gray values of pixels is required. After that we have calculate the degree of membership function because fuzzy logic is used to describe the fuzziness and it is possible by using degree of membership function shown in fig.4. The degree of membership is a curve which defines the values in between 0-1, as over which range the pixel values are varies. Again fuzzy logic is used to detect whether pixels are on edge or not. The fuzzy logic follows fuzzifiers and de-fuzzifiers and from this the fuzzy values are stores into fuzzy database. Fuzzy logic is easy to detect only edges and corners. But after classifiers; somewhat noise is present in the image. With the help of canny operator the output can sharpen and removes noise and consistent output is obtained. At the end of proposed system, according to formula of grain size the classification of different metals is shown in table. The type of the metal is detected automatically.

The application of proposed system is in metal industry because packing density of metal is depends on the size and shape of the grains.

\section{Extracting Grain Boundary by Fuzzy Logic}

After pre-processing, grain size analysis part is to be considered. The digital image is converted into gray scale image as input to the second part of system. Noise is present in image; due to defect present in the image while performing 
metallographic classes. At start, we select a pixel $\mathrm{P}(\mathrm{x}, \mathrm{y})$ from the image as a central middle point. A window W(x,y) is selected related to size of $\mathrm{n}$ in the pixel values as follows,

$$
\left[\begin{array}{ccccc}
\cdots & p(x-1, y-1) & p(x-1, y) & p(x-1, y+1) & \\
\ldots & p(x, y-1) & p(x, y) & p(x, y+1) & \ldots \\
& p(x+1, y-1) & p(x+1, y) & p(x+1, y+1) & \\
\ldots & & \ldots & &
\end{array}\right]
$$

Based on the analysis of above correlation of the pixels one new function is proposed i.e. $\mu(p)$, which calculates the membership degree. A degree of membership function is stated that each point presented in the input should be mapped perfectly between gray values 0 to 1 . We already know about fuzzy logic is used to describe the fuzziness. This fuzziness is utilized to characterize by its membership function.

In fuzzy logic the degree of truth is represented by membership function. Membership function describes all the information in fuzzy sets whether the elements from fuzzy sets are in discrete manner or in continuous manner. Membership function is a technique used to solve the practical problem rather than knowledge. The membership function $\mu(p)$ is expressed as follows,

$\mu(p)=\frac{1}{e^{[p(x, y)-a(x, y)]}}+1$

Where, $\mathrm{p}(\mathrm{x}, \mathrm{y})$ is gray value of the centre pixel in the $\mathrm{w}(\mathrm{x}, \mathrm{y}), \mu(p)$ is scalar value varies in between $[0,1]$ and $\mathrm{a}(\mathrm{x}, \mathrm{y})$ is the average value of all pixels from the window $w(x, y)$. The $a(x, y)$ is expressed as follows,

$a(x, y)=\frac{1}{n^{2}} \sum_{k-\left(x-\left(\frac{n-1}{2}\right)\right)}^{\left(x+\frac{n-1}{2}\right)} \sum_{1-\left(y-\left(\frac{n-1}{2}\right)\right)}^{\left(y+\left(\frac{n-1}{2}\right)\right)} p\left(k_{1}-1\right)$

As shown in fig.5, edge detected using fuzzy logic with consisting of some noises in the image. The grain boundary is a roof edge. The edge pixel central point $\mathrm{P}$ is considerably different from the adjacent non-edge pixels'. The edge pixels' are faint enough as compare to other pixels'. The gray converted value of the edge pixels' $\mathrm{P}$ is usually thinner than the non-edge pixels'. Depending on such features of the metallographic image, an edge detection algorithm utilizing fuzzy logic has been improved to detect the grain boundary from the frames. The fuzzy model is utilizes to compare the pixels' properties to determine whether the pixels' are on the edge or not. After edge detection using fuzzy logic detects some whole grains and some partial grains, to complete the grain shape morphological operations are used like dilation and erosion.

The output of morphological operation on image is as shown in fig.6. While final edge detected image is as shown in fig.7, to remove the noise from output of edge detected image filter is used and output is shown in the fig.8. Canny operator is considered to be much easier and consistent than other operators. Canny operator is only designed to detect the edges. It follows the gray values discontinuities output to show. An edge gives rise to ridges in the magnitude image by using canny operator. Fig.9 shows the result after canny operator processed to remove unwanted noise from image, while fig. 10, Shows the filtered output of canny operator.

\section{i. Fuzzy Model:}

Step 1: Take digital input image

Step 2: Convert digital input image into gray scale as fuzzy required binary values to detect edges.

Step 3: Locate $\mathrm{p}(\mathrm{x}, \mathrm{y})$ in window matrix

Step 4: Calculate d(i)

Step 5: Evaluate d(i) in input membership function.

Step 6: Apply fuzzy set of rules to window matrix

Step 7: Evaluate d(i) in input membership function.

Step 8: Defuzzification over system

Step 9: $x=$ width (Image)

True if $\mathrm{y}=\mathrm{y}+1 \& \mathrm{x}=0$

False if $x=x+1$

Step 10: $y=$ height (Image)

End if true

Again go to locate $p(x, y)$ if false. 


\section{Results}

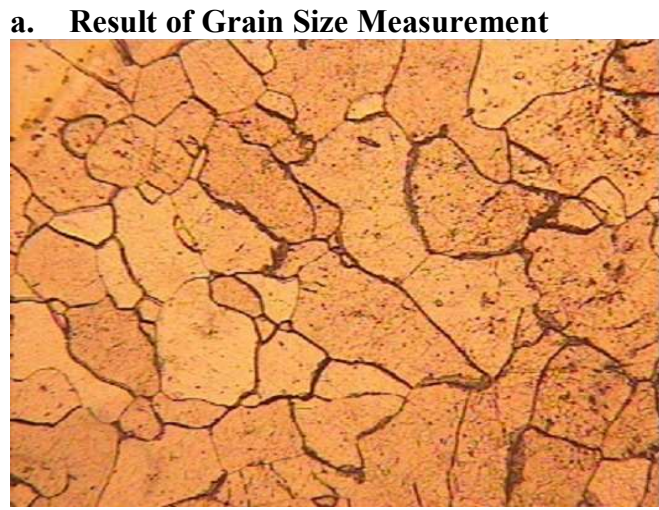

Figure 2: Digital Input Image
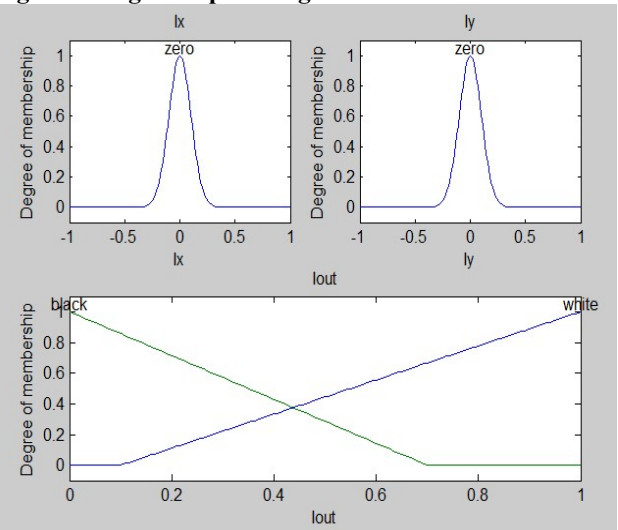

Figure 4: Degree of Membership Function $\mu(p)$

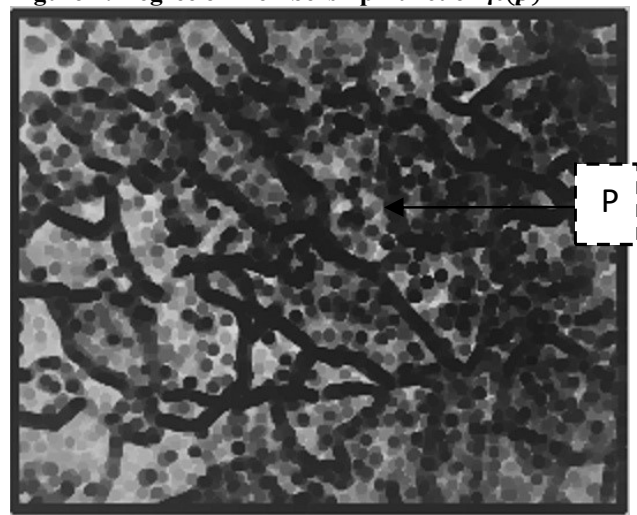

Figure 6: After Applying Morphological Operation on Image

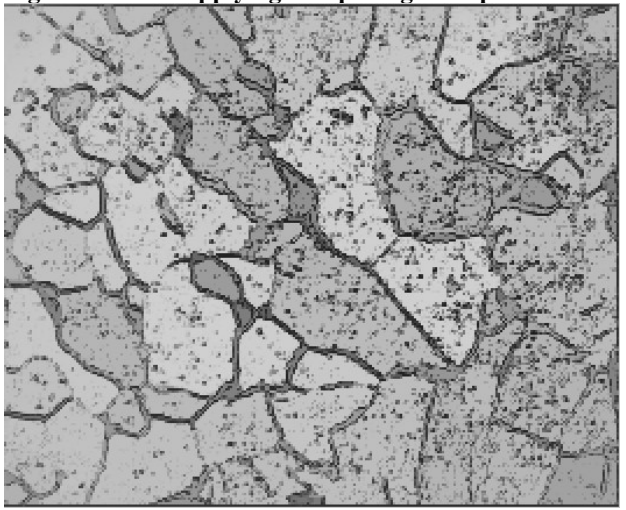

Figure 8: Filtered Image of Edge Detect

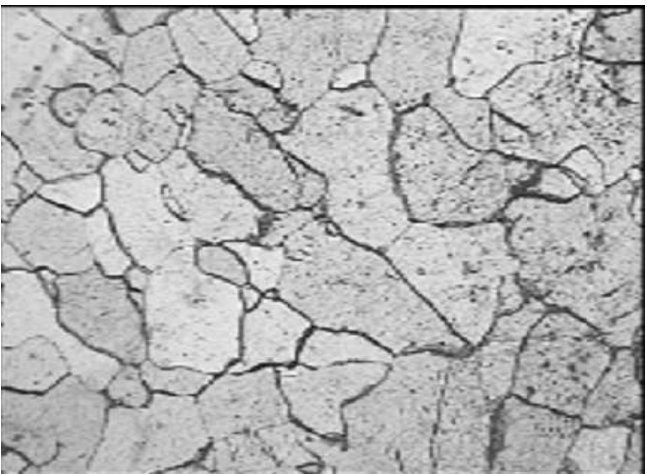

Figure 3: Digital Image Converted into Gray Scale

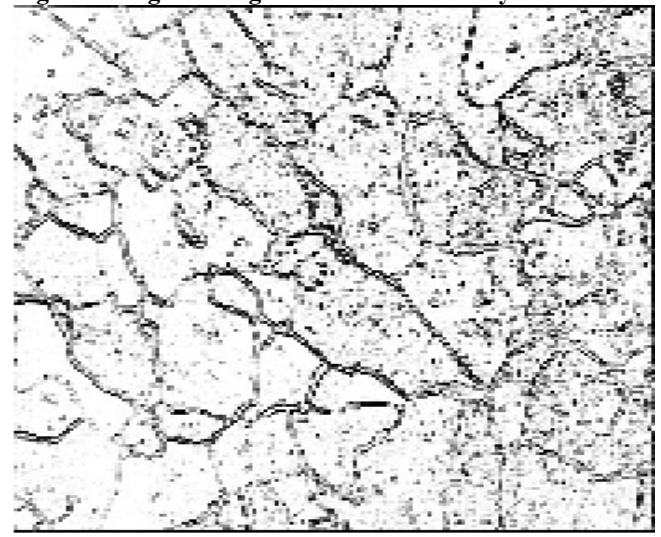

Figure 5: Output of the Edge Detection Using Fuzzy Logic

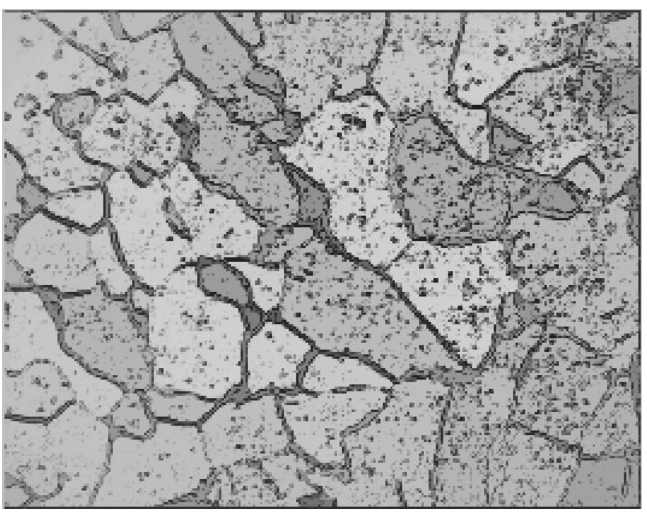

Figure 7: Edge Detected Using Fuzzy Model

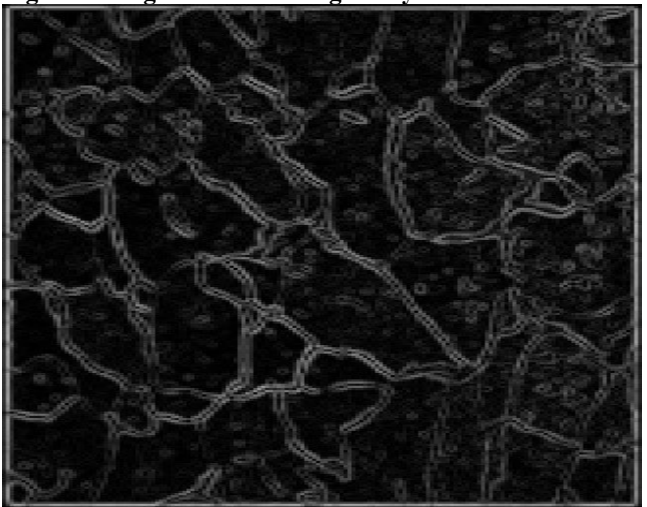

Figure 9: Results After Canny Operator Processed to Remove Unwanted Noise from Image. 


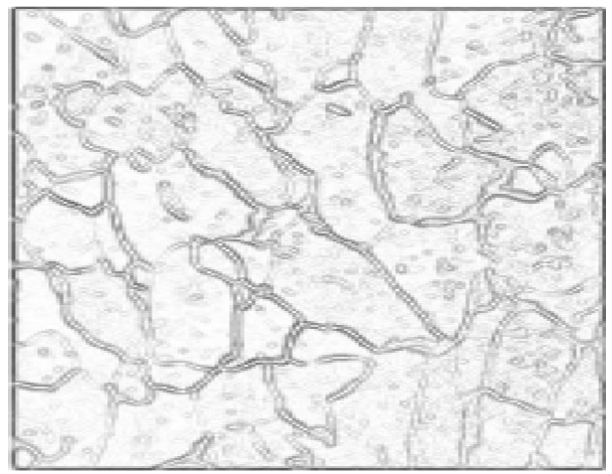

Figure 10: Final Filtered Image by Using the Canny Operator

Canny operator gives the smooth edges at the end of processing based on we determine the whole grains and partial grain easily for further calculations. Based on simulation part we calculate manually grain size and confirmed it by automatically. There are two methods are used to calculate the grain size first is simple formulae based while second is by using intercept method which shown below in fig.11,

\section{Method 1: (Simple)}

ASTM grain size number:

$N=2^{(n-1)}$

Where,

- $\quad$ N- No. Of Grains presented in the image

- $\mathrm{n}$ - Grain size no.

\section{Method 2: (Intercept Method)}

Grain size analyses by using intercept method as follows,

Step1: Calculate Magnification with the help of actual width and real width in $\mathrm{mm}$

Step2: Calculate mean intercept length by using formulae,

$$
l=\frac{(\text { no.of lines drawn }) *(\text { no of lines intercept per length } \mathrm{mm})}{M *(\# \text { of grains intercepted })}
$$

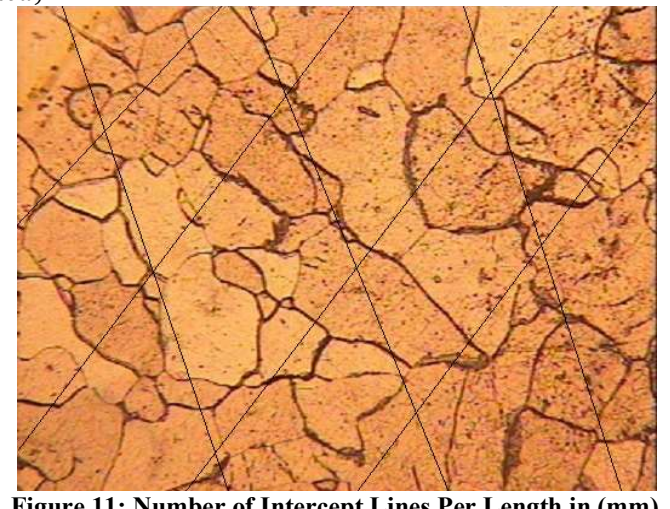

The above figure shows how to draw an intercept lines on image to calculate the grain size.

Step 3: Calculation of grain size according to formulae

$$
G=-6.643856 \log l-3.288
$$

Where,

- $\quad l$ - Mean intercept length

- M- Magnification

- $\quad$ G- Grain size

\begin{tabular}{|c|c|c|c|c|c|}
\hline Sr. No. & Alloy Name & $\begin{array}{c}\text { No of } \\
\text { Grains(N) }\end{array}$ & $\begin{array}{c}\text { Average Grain } \\
\text { Diameter(AVG) } \\
\text { (in mm) }\end{array}$ & $\begin{array}{c}\text { Grain Size } \\
(\mathrm{n}) \text { in } \mu \mathrm{m}\end{array}$ & $\begin{array}{c}\text { Values according to ASTM } \\
\text { Standard } \\
(\mu \mathrm{m})\end{array}$ \\
\hline 1 & A15052 & 377.10 & 0.01018 & 9.55 & $1-10[15]$ \\
\hline 2 & A11100 & 72.468 & 0.01167 & 7 & $1-10[15]$ \\
\hline 3 & A17075 & 71.88 & 0.02141 & 8 & $1-10[15]$ \\
\hline
\end{tabular}




\begin{tabular}{|c|c|c|c|c|c|}
\hline 4 & Al3003 & 18.20 & 0.02369 & 5 & $1-10[15]$ \\
\hline 5 & AZ 41A & 39.87 & 0.02035 & 6.31 & $3.8 \pm 1.6[21]$ \\
\hline 6 & AZ 31 & 6.8910 & 0.04681 & 3.78 & $3-35[16]$ \\
\hline 7 & Brass & 17.56 & 0.04107 & 5.13 & $3-5[17]$ \\
\hline 8 & Brass 1 & 16.47 & 0.04035 & 5.04 & $3-5[17]$ \\
\hline 9 & Brass 2 & 11.077 & 0.04777 & 4.46 & $3-5[17]$ \\
\hline 10 & AZ 41 & 4.816 & 0.01223 & 3.26 & $3.8 \pm 1.6[21]$ \\
\hline 11 & AZ 91D & 6.199 & 0.10205 & 18.89 & $\sim 15-100[18]$ \\
\hline 12 & Brass 3 & 11.62 & 0.03378 & 4.53 & $3-5[17]$ \\
\hline 13 & Brass 4 & 16.18 & 0.03299 & 5.01 & $3-5[17]$ \\
\hline 14 & Brass 5 & 18.08 & 0.02584 & 5.17 & $3-5[17]$ \\
\hline 15 & Brass 6 & 7.758 & 0.07318 & 3.95 & $3-5[17]$ \\
\hline
\end{tabular}

Table 1: Grain Size Calculation.

Where,

- $\quad$ Sr.No - Serial Number,

- $\quad$ ASTM - American society for testing material.

Observation from the above table it does prove that when numbers of Grains are increases the Grain Size also increases and vice versa. The star mark (*) shows that results are observed to be wrong. So, the Accuracy of system is calculated by using given formulae,

Accuracy $=\frac{\text { Corrected output }}{\text { Total size }}$

From the above equation the system accuracy is $\mathbf{8 0 \%}$. And table shows comparison with ASTM standard values of varieties metal alloys.

\begin{tabular}{|c|c|c|c|}
\hline Name of Alloys & $\begin{array}{c}\text { Proposed system results } \\
\text { (Grain Size in } \mu \mathrm{m})\end{array}$ & $\begin{array}{c}\text { Other researchers } \\
\text { results (Grain size in } \\
\mu \mathrm{m})[12]\end{array}$ & $\begin{array}{c}\text { Values according to ASTM } \\
\text { standard }(\mu \mathrm{m})\end{array}$ \\
\hline B4C & 18.52 & 19.3 & $10-60[20]$ \\
\hline B4C & 16.68 & 18.3 & $10-60[20]$ \\
\hline B4C+Al & 28.88 & 32.5 & $10-21[14]$ \\
\hline B4C+Al+Ni & 18.43 & 20.9 & $10-21[14]$ \\
\hline B4C+Al+Ni & 17.10 & 19.2 & $2.1-3.6[13]$ \\
\hline WC-Ni & 4.46 & 3.54 & $2.1-3.6[13]$ \\
\hline WC-Ni & 4.67 & 5.19 & $19]$ \\
\hline
\end{tabular}

Table 2: Comparison of Other Researcher's Result with Proposed System Results.

\section{b. Contribution to Proposed System}

In existing method only one type of metal is used and calculates Grain size of metal according to grain size formulas. While in proposed method, the system is working automatically as when we give digital image of metal as input then at the end which type of metal is used is detected. Comparison with other metals is also classified in the Table No. 3.

\section{Conclusion}

In this paper, we have presented a new combination of algorithms to do material analysis. To ensure the consistent changes, a material analysis is proposed approach to classify varieties of metal alloys of different types as shown in Table No.2\&3. We have compared the proposed results with existing work and also with ASTM standard. We have introduces material analysis/Grain size analysis according to their size/shape by using two new different methods like direct formulae based method and intercept method based on fuzzy logic. The output of proposed system, the grain size of particular metal is detected automatically. Experimental results on material analysis/Grain size analysis have shown the consistency of the proposed methods and its application. The results can also be improved by use of 3D images at input image. The use of pre-processing will be useful in detecting edges correctly.

\section{Acknowledgments}

We would like to thanks our reviewers for their constructive and valuable suggestions and comments to improve the quality of paper.

\section{References}

1. Shan L N, Li D Y, China Foundry Machinery \& Technology[J], vol. 4, 2005 January.

2. Grayali, N. and Shyne, J.C, Effect of microstructure and prior austenite grain size on acoustic velocity and attenuation in steel, Review of Progress In: Quantitative NDE 4, D.O. Thompson and D.E. Chimenti (Eds.), Plenum Press, New York:1985.p. 927-936. 
3. Palanichamy, P., Joseph, A.Jayakumar T. and Raj, B. Ultrasonic velocity measurements for estimation of grain size in austenitic stainless steel, NDT \& E International, vol: 28(3). p. 179-185, 1995.

4. Beecham, D. Ultrasonic scatter in metals: Its properties and its application to grain size determination, Ultrasonic, England: 1966, vol: 4 pp. 67-76.

5. Goebbels, K. and Höller, P., Quantitative determination of grain size and detection of in homogeneities in steel by ultrasonic backscattering measurements, Ultrasonic Material Characterization, H. Berger and M. Linzer (Eds.), Special publication 596, National Bureau of Standards, Gaithersburg, MD, pp. 67-74, 1980.

6. Hecht, A., Thiel, R., Neumann, E. and Mundry, E., Non destructive determination of grain size in austenitic sheet by ultrasonic backscattering, Materials Evaluation. Vol. 39, pp. 934-938. 1981.

7. Raul david serban., "Comparative grain-size measurements for validating sampling and pre-treatment techniques in terms of soli fluction landforms", southern carpathians, Romania. Journal of environmental geography journal of environmental geography; vol.8, No. (1-2), pp. 39-47, 2015.

8. S N Chirikov., "Comparison of particle size measurements of some aqueous suspensions by laser polarimetry and dynamic light scattering". II Conference on Plasma \& Laser Research and Technologies, Journal of Physics: Conference Series, pp. 012-051, 2016.

9. L.Xincheng, D.fei, Z.Weixing, F xiation, "Research on quantitative analysis method of steel dimples based on wavelet transform", In: International Conference on Mechanics automation and control Engineering (MACE), Wuhan, China, vol. 28, pp. 365-368, June 2010.

10. Ben Luan, An investigation on the coating of 3003 aluminum alloy, Surface \& Coatings Technology, vol. 186, pp. 431- 443, 2004.

11. Łukasz R, Łukasz S, Kusiak J., “Artificial Intelligence and Soft Computing [M]”, Heidelberg: Springer Berlin, vol. $80,2010$.

12. İsmail Hakk1 SARPÜN, "Determination of Mean Grain Size by Ultrasonic Methods of Tungsten Carbide and Boron Carbide Composites Sintered at Various Temperatures", 4 ${ }^{\text {th }}$ International conference on NDT, pp. 1-5, October 2017.

13. E.O. Correa, "Microstructure and mechanical properties of WC Ni-Si based cemented carbides developed by powder metallurgy", Int. Journal of Refractory Metals and Hard Materials, vol. 28, pp. 572-575, 2010.

14. V. Özkan, "Examining with the Sintered Temperature of Mean Grain Size of B4C-Al-Ni Composites by Ultrasonic Techniques", Proceedings of the International Congress on Advances in Applied Physics and Materials Science, Antalya, pp. 184-186, 2012.

15. https://www.olympus-ims.com/en/applications/grain-size-analysis/

16. S. Han, "Enhancing mechanical properties of AZ31 magnesium alloy through simultaneous addition of aluminum and nano-AI2O3", Proceedings of the ASME 2010 International Mechanical Engineering Congress \& Exposition IMECE2010 Vancouver, British Columbia, Canada, pp. 12-18, 2010.

17. Dhruv Anand, "Effect of thickness and grain size on flow stress of very thin brass sheets", 3rd International Conference on Materials Processing and Characterisation (ICMPC 2014), Procedia Materials Science, pp. 154 - 160 , 2014

18. K.D. Ralsto, Effect of Grain Size on Corrosion: A Review. Corrosion science section, vol. 66(7), pp. 1-13, March 2 2010.

19. E. Mohammad Sharifi, "Fabrication and evaluation of mechanical and tribological properties of boron carbide reinforced aluminum matrix nanocomposites", Materials and Design,vol. 32, pp.3263-3271, 2011.

20. Lembit Kommel, "Boron Carbide Based Composites Manufacturing and Recycling Features", materials science (MEDŽIAGOTYRA), vol.12, No.1, pp. 48-52. 2006.

21. Khin S. Tun, "Investigation on the Mechanical Properties of Mg-Al Alloys (AZ41 and AZ51) and Its Composites", Metals, vol.2, pp. 313-328, 2012.

22. Zhang Lixin, "Grain Size Automatic Determination for 7050 Al Alloy Based on a Fuzzy Logic Method", Rare Metal Materials and Engineering, vol.45, No.3, pp. 0548-0554, 2016.

23. Sapkal A M, Bairagi V, "Telemedicine in India: a review challenges and role of image compression", Journal of Medical Imaging Health Inform 1(4), 300-306, 2011

24. Prakash B Gaikwad, V.K.Bairagi, "Hand Gesture Recognition for Dumb People using Indian Sign Language", International Journal of Advanced Research in computer Science and Software Engineering, pp:193-194, 2014.

25. P. Bohr, R. Gargote, R. Vhorkate, R.U. Yawle, V. K. Bairagi, "A No Reference Image Blur Detection Using Cumulative probability Blur Detection (CPBD) Metric", International Journal of Science and Modern Engineering, vol. 1, no. 5, April 2013.

26. Kulkarni N, Bairagi VK, "Diagnosis of Alzheimer disease using EEG signals". International Journal of Engineering Research \& Technology (IJERT) 3(4):1835-1838, 2014.

27. Vinayak K. Bairagi \& Ashok M. Sapkal \& Ankita Tapaswi: Texture-Based Medical Image Compression, Springer Journal of Digital Imaging 26:65-71, 2013 